\title{
Snow insulation and conservation systems
}

\author{
Karapet Ter-Zakaryan ${ }^{1}$, Armen Grigoryan ${ }^{2}$, Andrey Medvedev ${ }^{3, *}$, Boris Efimov ${ }^{3}$, Aleksey \\ Poserenin $^{4}$ \\ ${ }^{1}$ Itd TEPOFOL, 105318, 3 Shcherbakovskaya str., of. 810, Moscow, Russia \\ ${ }^{2}$ NPO Yerevan Youth Sports School of Shooting, 0096, 4/3 Vilnius str., Yerevan, Republic of \\ Armenia \\ ${ }^{3}$ Moscow State University of Civil Engineering, 129337, Yaroslavskoye shosse, 26, Moscow, Russia \\ ${ }^{4}$ Russian State Geological Prospecting University, 117997, Miklukcho-Maklaya, 23, Moscow, Russia
}

\begin{abstract}
Various aspects of application of polyethylene foam implemented for roof thermal insulation within the frame of one of the sports venues and, closely, the realization of insulation systems for cold conservation on the territory of public sports facilities, particularly for snow storage conservation within ski resorts have been regarded in this article. Additional demands are placed on thermal insulating material for suchlike constructions. Apart from high thermo technical properties, the material should involve hermeticity, lightness, easy mounting and maintenance, durability, bacterial and fungal resistance and temperature differential resistance. The examination results concerning properties and particularities of application of non-cross-linked polyethylene foam within the scope of production of insulation coatings protecting the snow from melting are given in the article. It has been established that being the part of insulation system polyethylene foam preserves the accuracy of mechanical and thermo physical characteristics. Taking all functional particularities of insulation systems implementation into consideration, the principles of protection and conservation of snow covering have been developed being realized on the mountainsides and plateaus of ski resorts. Polyethylene foam rolls have been connected in a butt joint and mechanically fixed. As a result, a seamless insulating coating - thermal blanket has been formed, which covered the entire mountainside. Maintenance of insulation system is performed during the off-season between March and September in the period of stable positive temperatures.
\end{abstract}

\section{Introduction}

The main function of insulating materials and products is creation of insulating envelopes; however, the application of thermal insulation may be detailed from the point of view of the result [1-4]. First, formation of thermal insulating envelopes is focused on the reduction of heat losses from inside outwards. The designing and implementation of the majority of construction systems is based on this functional solution. On the second hand,

\footnotetext{
* Corresponding author: medvedev747@yandex.ru
} 
this includes protection of building structures and indoor premises from overheating. Thirdly, it is about cold conservation in special plants and at special facilities such as refrigerators, sports venues, etc. [5-8].

The remarkable thing is that the effective protecting envelope with highly-efficient thermal insulating material characterized by stable properties and minimum amount of heat transfer surface areas - cold bridges allows reducing energy expenses on refrigerating plants operation by $40-60 \%$ what determinates the reasonability of application of insulation systems [9-11].

\section{Materials and methods}

This paper concentrates on conservation problem of snow covering at ski resorts. For regions, where alpine tourism serves as a significant income item and source of economic stability, the highest possible increase of ski resorts exploitation represents primary objective. The last year's snow being saved for the entire warm season and allowing touristic routes to become opened 2-3 weeks earlier (starting with the first stable negative temperatures), i.e. before climatic snow falling, is of a great help in this case.

Noteworthy is that in the most cases the woodchips and sawdust are continuing to be used in the quality of insulating barriers for protection the snow from melting (as a fill up to $1,000 \mathrm{~mm}$ in thickness). This provides the snow preservation by $60-80 \%$, but leads to the problem of recycling of used sawdust and low energy conversion efficiency of the insulation system as a whole [12-14].

Minimization of heat transfer through the insulating barriers is determined by the following factors. First, these are the properties of a heat-insulating material (density, thermal conductivity, vapor permeability, water absorption); secondly, the presence of heat bridges and heat-conducting inclusions; thirdly, the condition of the coating at the joints of separate heat-insulating sheets; fourthly, the stability of insulation material properties for the entire exploitation period, and, fifthly, the durability of the insulation system [15-17].

Additional demands are placed on thermal insulating material for suchlike constructions. Apart from high thermo technical properties, the material should involve hermeticity, lightness, easy mounting and maintenance, durability, bacterial and fungal resistance and temperature differential resistance. In this regard, rolled polyethylene foam is worthwhile being an elastic material, resistant to the impacts of temperature, humidity, aggressive components contained in the air what determinates its high operational durability [18-20].

\section{Results}

Following characteristics of polyethylene foam have been experimentally proven: the longitudinal tensile strength of the polyethylene foam products with a metallized coating is 80-92 kPa, without metallized coating - 80-87 kPa, and 29-32 kPa of the weld seam. Thermal conductivity of the material lies within the range of $0,026-0,034 \mathrm{~W} /(\mathrm{m} \cdot \mathrm{K})$.

It has been established that the values of diffusion moisture absorption of polyethylene foam with an average density of $18-20 \mathrm{~kg} / \mathrm{m} 3$ amounts to $0.44 \mathrm{~kg} / \mathrm{m} 2$ without a metallized coating and $0.37 \mathrm{~kg} / \mathrm{m} 2$ with a metallized coating; water absorption after partial immersion in water for 24 hours is equal to $0,013 \mathrm{~kg} / \mathrm{m} 2$; water absorption by volume after complete water immersion for 28 days amounts to $0.96 \%$. Polyethylene foam is applicable under conditions of negative (from $-60{ }^{\circ} \mathrm{C}$ ) and alternating temperatures. It is found that the change of polyethylene foam properties within the frame of examined temperature interval (from -60 to $+80{ }^{\circ} \mathrm{C}$ ) does not exceed the experimental error. 
The material practically does not change its properties under conditions of long-term alternating changes as well as by simultaneous humidity impact. Polyethylene foam is an inflammable material the same as other foamed plastics what should be necessarily taken into consideration by developing of its application systems [21, 22].

\section{Discussions}

The originality of the material and developed Tepofol technology (RU Patent No. 2645190) in comparison with known solutions involves elaboration of rolled polyethylene foam of 20 to $150 \mathrm{~mm}$ in thickness with a locking joint as well as technology of seamless connection of separate thermal insulating canvases. Polyethylene foam rolls produced by means of extrusion are mechanically fixed and connected with the help of the lock joint. The locking system in its turn is welded at the junction of two rolls by means of a hot air gun. In case the welding is not possible, provision is made for mechanical connection systems of sheets.

The insulation systems of various purposes have been implemented within the frame of one of the resort facilities. On the first hand, the Youth Sports School of Shooting of Yerevan was reconstructed. The building project has been renovated in 2009 but both roof leakages and pseudo roof leakages have occurred quite quickly. After long professional discussions the decision was made in favor of Tepofol as the best versatile material for thermal insulation, vapor barrier, soundproofing and as a comprehension solution of an assigned task. Secondly, the snow conservation technology has been tested.

The application of Tepofol polyethylene foam rolls with a metallized coating and locking joint has technically proven its value when developing snow conservation technology in the off-season (from spring to fall) for the purpose of its early usage at ski resorts or aiming to preserve the snow in order to compensate its deficiency by insufficient natural snowfall in the winter period on the ski runs of any type.

Implementing of such a broad challenge has involved two stages. At the first stage tons of snow are either produced with the help of snow cannons, or banked from the flanks into large piles and stored at special sites. The artificial snow is mixed with the natural snow and then compressed (Fig. 1).

If snow storage sites are located in hard-to-reach areas, then thermal insulation is delivered in rolls to the storage area by helicopters, if storage takes place in the field or in glens (pits, large gullies), then delivery is accomplished by any suitable type of transport.

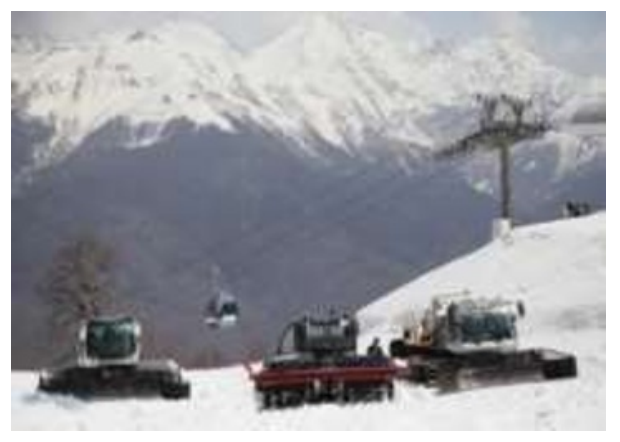

a)

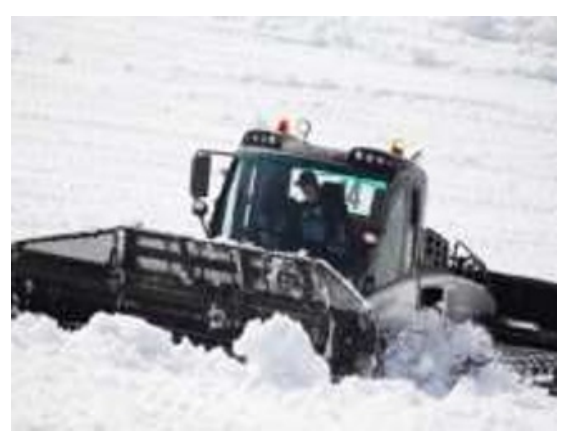


b)
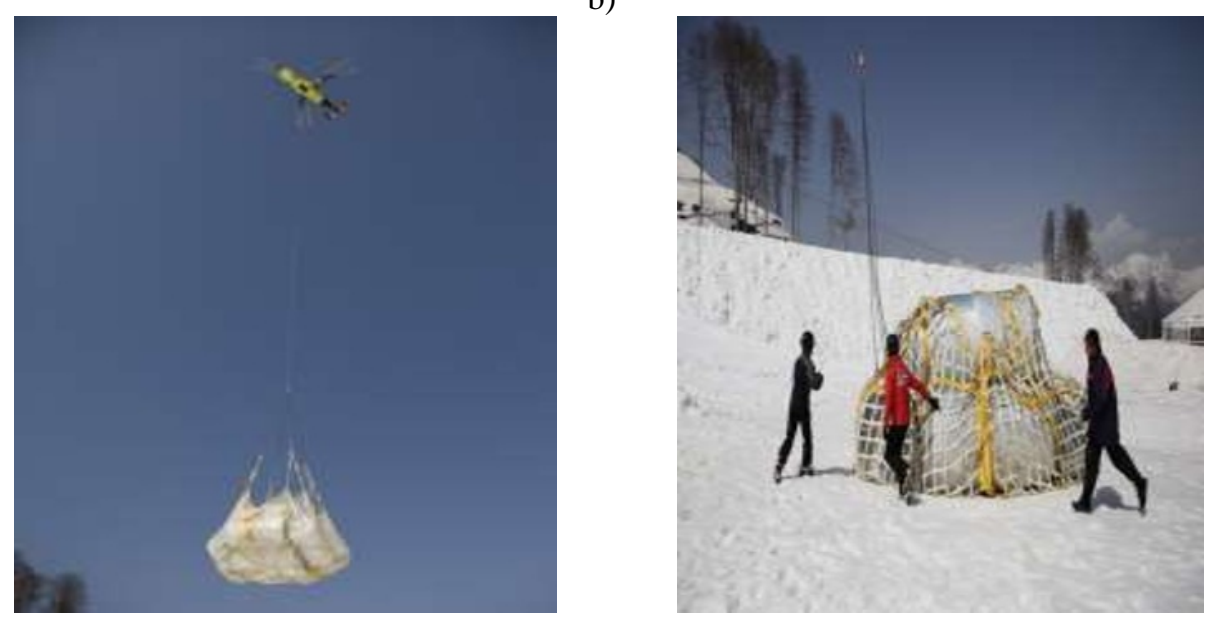

c)
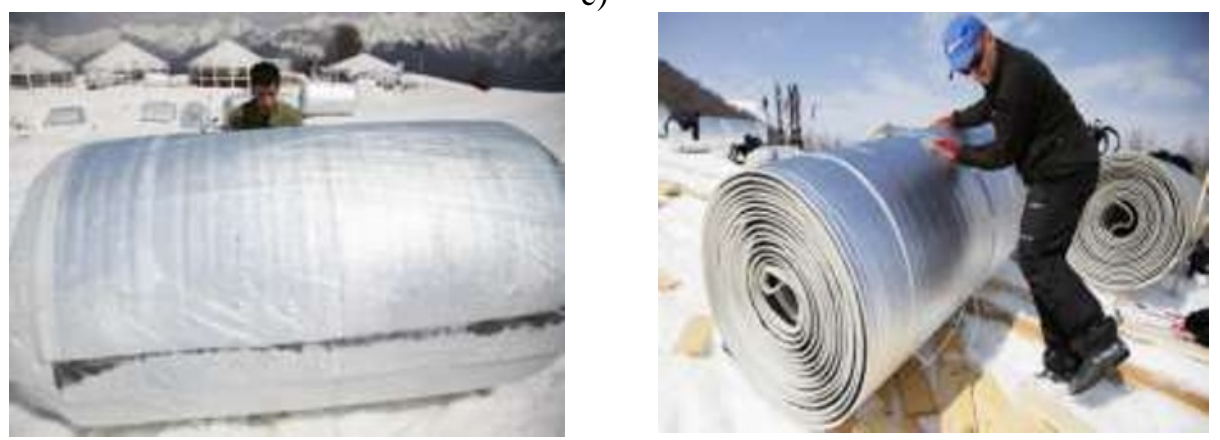

Fig. 1. Preparatory stage of installation of a protective coating with the help of rolled polyethylene foam: a - snow collecting for conservation by means of construction equipment and its compressing; $\mathrm{b}$ - delivery of polyethylene foam rolls; $\mathrm{c}$ - preparation of rolls.

Polyethylene foam rolls are prepared and laid on the insulating surface being subsequently connected in order to achieve an integral seamless canvas. Conservation of snow storage is per-formed with the help of polyethylene foam rolls of $20-50 \mathrm{~mm}$ in thickness with metallized coating. In order to expand the durability of insulation system and enable its repeated usage, the arrangement of a tent is recommended, which is fixed along the perimeter of the snow storage and surface area with the help of tension structures: ropes that are also fastened along the perimeter and represent a net (Fig. 2).

a)
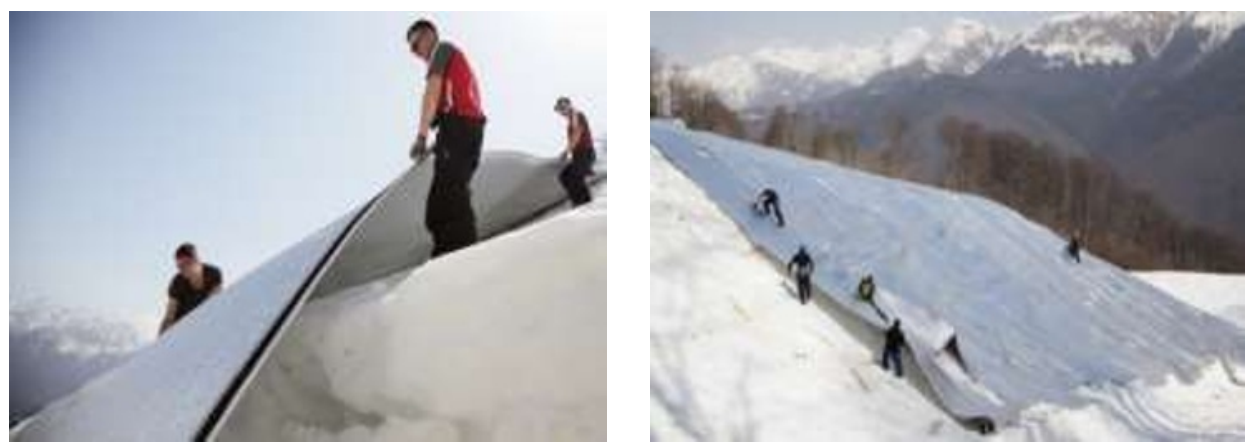
b)

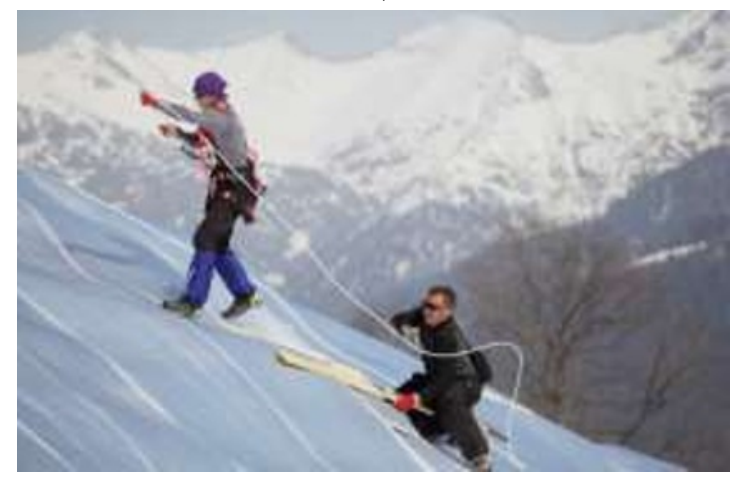

c)
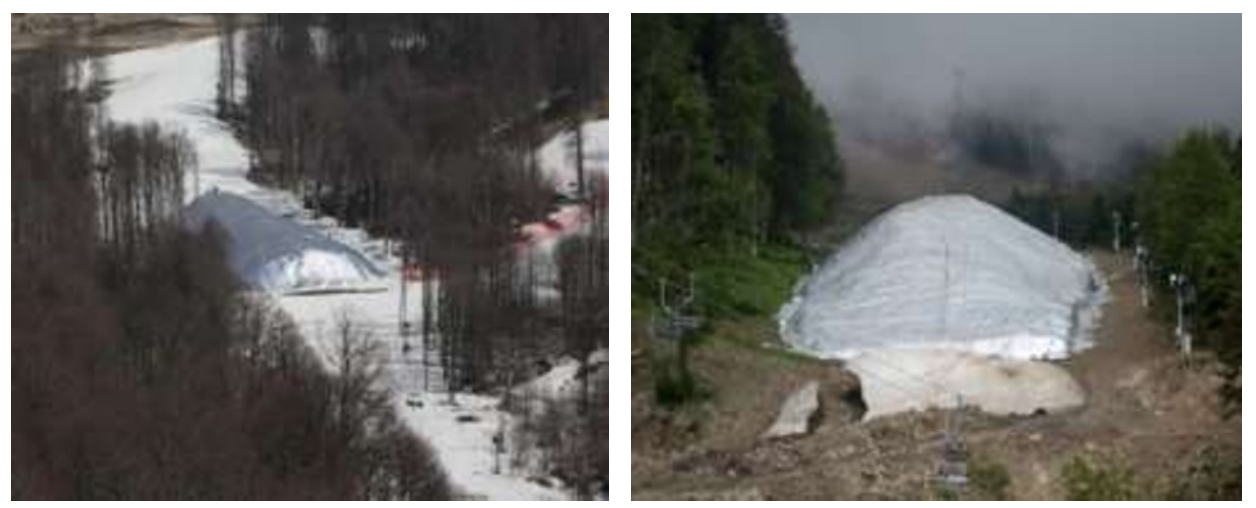

Fig. 2. Arrangement of a protective coating with the help of rolled polyethylene foam (snow conservation) and its exploitation: $\mathrm{a}$ - laying the rolls out; $\mathrm{b}$ - rolls junction in a seamless insulating coating; $\mathrm{c}$ - snow reserves kept during the off-season.

From the point of view of thermophysics and heat-exchanging processes, following phenomena are in evidence in this case. First and foremost, polyethylene foam has a low thermal conductivity, as well as vapor permeability and water absorption and its properties do not practically change in the considered operating conditions. Secondly, the locking junction of the rolls allows minimizing the bridges of heat transfer at the joints and creates a seamless insulating coating. Thirdly, the snow itself has a relatively high heat capacity (of about $2,080-2,100 \mathrm{~J} /\left(\mathrm{kg} \cdot{ }^{\circ} \mathrm{C}\right)$ and relatively low thermal conductivity. By the density of soft snow of $200 \mathrm{~kg} / \mathrm{m}^{3}$ its thermal conductivity is equal to $0.15 \mathrm{~W} /(\mathrm{m} \cdot \mathrm{K})$, and the density of compacted snow amounts $600-700 \mathrm{~kg} / \mathrm{m}^{3}$ by thermal conductivity $-0.6-0.7 \mathrm{~W} /(\mathrm{m} \cdot \mathrm{K})$.

The metallized surface of the rolled polyethylene foam reflects the sun rays and it is also recommended to choose the tented covering in light tones in order to achieve the sun rays reflection as well. The specified factors allow obtaining the thermal resistance of the insulating coating ("thermal blanket") of about $1.3 \mathrm{~W} / \mathrm{m}^{2}{ }^{\circ} \mathrm{C}$, and, taking the thermal resistance of the snow mass into account, even higher.

Considering all the operational characteristics of the implementation of insulation systems for snow preservation, the principles of protection and preservation (conservation) of snow covering have been developed, implemented on the hillside and plain sportstouristic facilities. 


\section{Conclusion}

Polyethylene foam rolls became the base, and a special technology was developed on its basis - snow conservation with the help of "thermal blanket". Therefore, a seamless insulating coating was created which covered the entire hillside. The snowy hills of the ski resort have been covered with this giant integral insulating coating that had to be moved even with the help of aircraft.

Heat-insulating products based on the polyethylene foam are environmentally-friendly, easy-to-install and user-friendly and are also characterized by high operational durability. The possibility of creating a seamless coating minimizes the heat-conducting bridges along the smooth surface of constructions.

Systems based on polyethylene foam represent a clear example of the implementation of energy efficiency principles. In the context of snow conservation technology these principles can be formulated as follows: cold conservation in insulating volumes achievable by means of creation of insulating coating, enables snow preservation without application of additional cold sources and consequently promote energy resource saving.

Usage of material and structures based on "Tepofol Thermal blanket" system assumes realization of quick and non-energy intensive building process; creation of optimal working conditions for maintenance of insulating materials under conditions of people presence.

It has been established that the performance characteristics of polyethylene foam, as well as insulation coatings on its base, comply completely with the requirements to the materials and systems operating under conditions of negative and alternating temperatures. Creation of a seamless joint as an effect of the locking connection of separate rolls of polyethylene foam enables maintaining the temperature conditions in the insulating volume. Cold conservation technology was tested within the construction process of specialized facilities, when insulating sports venues, as well as in field conditions for snow conservation.

\section{References}

1. A.D. Zhukov, E.Yu. Bobrova, D.B. Zelenshchikov, R.M. Mustafaev, A.O. Khimich, Insulation systems and green sustainable construction, 1025-1026 (2014)

2. B.M. Rumiantcev, A.D. Zhukov, D.B. Zelenshikov, A.S. Chkunin, K.K. Ivanov, Yu.V. Sazonova, Insulation systems of the building construtions. MATEC Web of Conferences, 86 (2016)

3. B.M. Rumiantcev, A.D. Zhukov, E.Yu. Bobrova, I.P. Romanova, D.B. Zelenshikov, T.V. Smirnova, The systems of insulation and a methodology for assessing the durability. MATEC Web of Conferences, 86 (2016)

4. P.M. Zhuk, A.D. Zhukov, Normative legal base of environmental assessment of building materials: prospects for improvement. Ecology and industry of Russia, 4 (2018)

5. Patent for Russian Federation invention no. 2645190 " lock technology of thermal insulation material for seamless welding of connecting locks», registered on February $16^{\text {th }}(2018)$

6. A.D. Zhukov, K.A. Ter-Zakaryan, V.S. Semenov, Insulation systems with the expanded polyethylene application. ScienceDirect IFAC PaperOnLine, 51, 30 (2018)

7. A.D. Zhukov, T.V. Konoval'tseva, E.Yu. Bobrova, E.A. Zinovieva, K.K. Ivanov, Thermal insulation: operational properties and methods of research. IPICSE (2018) 
8. Alpatov, V., Balzannikov, M.: IOP Conference Series: Materials Science and Engineering 456(1), p. 012011 (2018). DOI: 10.1088/1757-899X/456/1/012011

9. Nilova, L., Naumenko, N., Kalinina, I.: A study of the forms of bound water in bread and bakery products using differential thermal analysis, Agronomy Research, 15 (2), 1386-1398 (2017)

10. E. Bobrova, A. Pilipenko, A. Zhukov, Insulating sheath system and energy efficiency of buildings. TPACEE (2018)

11. A. Zhukov, T. Dovydenko, S. Kozlov, K. Ter-Zakaryan, E. Bobrova, Innovative technologies for low-rise construction. TPACEE (2018)

12. Kosnikov, S.N., Khaibullina, I.V., Ignatskaya, M.A., Bakharev, V.V., Pinchuk, V.N.: International Journal of Applied Business and Economic Research, 15(13), c. 243-253 (2017)

13. Alpatov, V., IOP Conference Series: Materials Science and Engineering 463(3), p. 032102 (2018). DOI: 10.1088/1757-899X/463/3/032102

14. A.D. Zhukov, K.A. Ter-Zakaryan, I.V. Bessonov, V.S. Semenov, A.V. Starostin, Insulation systems for frame cottages. ACADEMIA, 1 (2019)

15. A.D. Zhukov, E.Yu. Bobrova, I.V. Bessonov, Construction systems and features of the use of heat-insulating materials. Housing construction, 7 (2015)

16. A.D. Zhukov, A.V. Zayfarov, V.A. Vlasenko, E.A. Zinovyeva, Insulation systems for low-energy homes. Innovations in life, №2 (2017)

17. A.D. Zhukov, B.A. Efimov, Yu.V. Sazonova, A.Yu. Zhukov, Polyethylene as thermal insulation for cold climates. Scientific Review, 7 (2017)

18. A.D. Zhukov, K.A. Ter-Zakaryan, A.V. Zayafarov, E.S. Petrovsky, D.U. Tuchaev, Systems of insulation of pitched roofs. Roofing and insulating materials, 6 (2017)

19. A.D. Zhukov, K.A. Ter-Zakaryan, D.U. Tuchaev, E.S. Petrovsky, Energy-efficient insulation of food warehouses and vegetable stores. International Agricultural Journal, 1 (2018)

20. A.D. Zhukov, K.A. Ter-Zakaryan, S.D. Kozlov, A.Yu. Zhukov, Seamless Isolation in Floating Floor Systems. Housing construction, 9 (2018)

21. A.D. Zhukov, V.S. Semenov, K.A. Ter-Zakaryan, Yu.V. Sazonova, Features of the implementation of insulation systems in the Far North. Construction materials, 4 (2018)

22. A.D. Zhukov, K.A. Ter-Zakaryan, I.V. Bessonov, V.S. Semenov, A.V. Starostin, Systems of building insulation with the use of polyethylene foam. Construction materials, 9 (2018) 